\title{
A suposta modernização das relações de trabalho nas incubadoras de empreendimentos
}

\author{
Deborah Moraes Zouain* \\ Luciana Silva Torres**
}

\section{Resumo}

Muito se tem escrito sobre a desigualdade social nos países subdesenvolvidos e a incapacidade do Estado de garantir 0 exercício da cidadania a todos os indivíduos. Para muitos, foi o acelerado desenvolvimento da microinformática que consolidou a globalização, acirrando a desigualdade, tanto interna quanto entre países, e estabelecendo uma rede de conflitos. Simultaneamente, surgiram no Brasil novas formas de organização com a proposta de colaborar com o Estado na mobilização de setores socioeconômicos, visando ao resgate da cidadania dos excluídos. É o caso das associações da sociedade civil - formadoras do chamado terceiro setor - e das incubadoras de empresas; geralmente, criadas em universidades e institutos de pesquisa. Nessa discussão, o conceito de inclusão se torna mais amplo, pois agora não basta assegurar educação, saúde e renda, mas também incentivar a reflexão, a iniciativa e a autonomia, num processo que muitos chamam de empreendedorismo humano. A idéia é romper com o paradigma fordista (Tenório: 2000) do início do século XX, principalmente quanto às relações de trabalho. No caso do Brasil, o objetivo é conceber novas formas de organização que respondam às características do modelo de desenvolvimento do país, baseadas em modelos americanos de empreendedorismo social e econômico, mas apropriando-se desse modelo de forma crítica (Guerreiro Ramos: 1965). Apesar dos muitos desvios, boa parte dessas organizações tem sido bem-sucedida, no mínimo, pela criação de novos postos de trabalho; primeiro passo para 0 desenvolvimento social. Nesse sentido, este artigo pretende analisar supostas inovações nas relações de trabalho nas incubadoras de empreendimentos.

Palavras-chave: trabalho; incubadoras de empreendimentos.

\begin{abstract}
A great deal has been written about social inequality in less developed countries and about the lack of ability of the State to guarantee civic rights to all the individuals to whom it owes this commitment. It is claimed that it was the rapid development of microinformation technology that guaranteed the intensification of globalization and led to the increase in social inequality among countries and within nations, in a knock-on process of conflict. Parallel to this movement, new forms of human organizations have arisen in Brazil setting out to collaborate with the State in the mobilization of socioeconomic sectors. The purpose is to redress the civic rights of excluded individuals, mainly by means of civil associations that comprise the Tertiary Sector, and of company incubators usually originating in universities and research institutions. In this discussion, the inclusion concept becomes broader in scope, as it is no longer sufficient to guarantee education, health and income. What is needed is motivation towards reflection, initiative and autonomy, in what many have called human entrepreneurship. The idea was to make a clean break with the Fordist paradigm (Tenorio: 2000) of the beginning of the twentieth century, mainly with respect to work relationships, and to conceive of new forms of organizations to cater to genuinely Brazilian characteristics of development. These new models were based on American models of social and economical entrepreneurship, but with due critical appropriation achieved in the sociological reduction by Guerreiro Ramos' (1965). There have been many thwarted attempts, however, a lot of these organizations follow a successful path, which at least leads to the creation of new job openings, which is the first step on the road to social development. This work presents an analysis of the innovations in work relationships allegedly to be found in company incubators.
\end{abstract}

Key-words: Work, Company Incubators.

\footnotetext{
* Vice-Diretora da Escola Brasileira de Administração Pública e de Empresas (EBAPE), Fundação Getulio Vargas (FGV) e Chefe do Centro de Formação Acadêmica e Pesquisa (CFAP), da EBAPE/FGV E- mail: deborah@ fgv.br. Endereço: Praia de Botafogo, 190 - 50 andar - Botafogo CEP: 22.250-900.

** Professora-assistente da Universidade Federal do Rio de Janeiro (UNIRIO) e administradora industrial pelo Centro Federal de Educação Tecnológica Celso Suckow da Fonseca (CEFET/RJ). E-mail: LUCIANA@ fgvmail.br. Endereço: Av. Pasteur, 296 - Urca - CEP: 22290-240.

Artigo aceito para publicação em novembro de 2004 e aceito em março de 2005.
} 


\section{Introdução}

A desigualdade social acompanha a história do Brasil e, do ponto de vista da trajetória humana, sempre ocorreu entre as nações. Na sociedade brasileira, a imagem que se tem da pobreza adquiriu diferente contornos ao longo do tempo. Na virada do século passado, os pobres, em sua maioria negros e afro-descendentes, eram vistos como perigosos, por não se sujeitarem ao assalariamento e à possibilidade de outro tipo de escravidão. Nos anos 1950-60, a pobreza é reconhecida como questão social, sendo vista como resultado da falta de oportunidades e do conseqüente crescimento do subemprego, fatores que levaram ao crescimento da população de baixa renda, como era então chamada a classe pobre urbana. Já nas décadas de 1970-80, a pobreza se generaliza, pois já não há mais empregos, mas estratégias de sobrevivência que resultaram na expansão da informalidade na economia. É nesse momento que ocorre a distinção entre trabalhadores pobres e bandidos, até então confundidos no imaginário nacional.

Nesse contexto, os índices de desigualdade social nunca foram tão elevados. A miséria absoluta convive com a mais refinada tecnologia de preservação da vida, através do avanço da genética, num momento histórico cheio de contradições. O homem descobre novas armas de guerra a partir de genes de animais e não descobre a si mesmo, incapaz de descobrir tecnologias que garantam a vida e a paz. O homem passa por quem está abandonado nas ruas e, muitas vezes, não se sensibiliza, nem se torna generoso. Para o aprendizado mais difícil da humanidade ainda não se teve muitos progressos, o amor a si mesmo e ao semelhante. Nas palavras de Freire:

A grande generosidade está em lutar para que, cada vez mais, estas mãos, sejam de homens ou de povos; se estendam menos, em gestos de súplica. Súplica de humildes a poderosos. E se vão fazendo, cada vez mais, mãos humanas, que trabalhem e transformem o mundo... Lutando pela restauração de sua humanidade estarão, sejam homens ou povos, tentando a restauração da generosidade verdadeira (FREIRE, 2002, p.31).

A guerra é parte da história humana desde os mais remotos tempos. A sofisticação crescente das armas torna as batalhas cada vez menos visíveis, e a lutas travadas, construções simbólicas que deterioram nossos valores, fazendo com que freqüentemente nem se saiba que havia uma batalha a ser conquistada.Os povos subdesenvolvidos - segundo os padrões da Europa Ocidental, principalmente da Inglaterra - sempre se viram, desde o primeiro encontro com o europeu, como pertencentes a uma etnia inferior, a ser "civilizada". Seres que deveriam abrir mão de sua noção de tempo orientada pelas fases da lua e adotar o calendário cristão. Seres que deveriam abrir mão da fé em seus deuses e nas energias da natureza para adotar o cristianismo. Esses povos acreditaram que evoluir era se parecer com o dominador, ainda que ao longo do tempo, mais e mais se evidenciasse o valor de suas culturas.

Segundo Elias (1994), o conceito de civilização serve para que a sociedade ocidental imponha sua tecnologia, seus hábitos, seu desenvolvimento científico e sua visão do mundo, atribuindo a si própria um caráter especial.. Em suma, define o seu orgulho pela importância de suas nações para o progresso do Ocidente e da humanidade. Contudo, Elias afirma que esse entendimento não é partilhado por todas as nações ocidentais; muito menos, pelo resto do mundo. Mesmo assim, é o conceito ensinado na escola, mesmo fora da Europa Ocidental, o que fez com que países como o Brasil vissem a si mesmos como incapazes de se tornarem nações civilizadas, aptas a dar sua contribuição para o progresso da humanidade ou, ao menos, de promover seu próprio desenvolvimento.

O Brasil sofre com a desigualdade social e o subdesenvolvimento, quando tem uma pequena parcela de sua população vivendo "civilizadamente", enquanto a maioria sobrevive de suas migalhas, não raras vezes, sujeita a duras condições de trabalho, sofrendo o que pode ser definido como uma forma de assédio moral.

Para Hirigoyen (2002), um indivíduo pode destruir o outro pelo contínuo assédio moral, num processo de ataque à identidade deste, de quem procura eliminar toda a individualidade. Seguindo esse raciocínio, Guerreiro-Ramos (1965) afirmava, há décadas, que para se desenvolver, o país tinha de estabelecer um projeto 
coletivo de construção de uma personalidade histórica. Para ele, o país teria de querer "assenhorear-se de sua realidade e determinar-se a si próprio". O alerta, no entanto, não foi suficiente para reverter o quadro, visto que ainda hoje, as iniciativas brasileiras nesse sentido podem ser consideradas pífias.

De acordo com Bourdieu (1989), a ordem mundial segue um processo de construção da realidade pela disseminação de símbolos das culturas dominantes:

A cultura dominante contribui para a integração real da classe dominante (assegurando uma comunicação imediata entre todos os seus membros e distinguindo-os das outras classes); para a integração fictícia da sociedade no seu conjunto; portanto, à desmobilização (falsa consciência) das classes dominadas; para a legitimação da ordem estabelecida por meio do estabelecimento das distinções (hierarquias) e para a legitimação dessas distinções (BOURDIEU, 1989, p.30).

Nesse mesmo sentido, Guerreiro-Ramos (1965) afirmou que a ciência da organização deveria avançar no sentido de um entendimento da política cognitiva, avaliando o uso consciente ou inconsciente da linguagem distorcida que leva os indivíduos a interpretarem a realidade em termos convenientes aos interesses dos agentes dessa distorção.

O povo brasileiro sempre foi moralmente assediado e aproveita o seu ócio criativo, gerado pelo desemprego, o subemprego e a miséria, para viver de uma economia informal que acaba com a fome apenas temporariamente e com as reais possibilidades de progresso. Essa é a grande diferença entre o ócio criativo proposto por de Masi (2000) - a educação que possibilita ao povo aproveitar sua criatividade para viver melhor - e a simples luta pela sobrevivência.

É possível afirmar que as causas da pobreza são individuais, coletivas e globais. Individuais porque cada um deveria fazer a sua parte e não compactuar com a ordem estabelecida. Coletivas porque as interações e a cooperação são meios para unir essas individualidades na conquista de algo comum ao desenvolvimento. Globais porque a união das individualidades para a dominação econômica e cultural entre os países gerou a necessidade de uma reação contrária, no sentido da auto-afirmação da identidade cultural das nações que se posicionaram de forma diferente da determinada pelas nações desenvolvidas. Nesse caso, trata-se de povos que não querem organizações não-governamentais recebendo fundos estrangeiros para o desenvolvimento de projetos assistencialistas nem projetos de inclusão social. Querem educação de qualidade para mudarem seus próprios destinos, com autonomia e auto-estima elevada, num verdadeiro processo de inclusão social.

\section{0 novo papel do Estado}

Com o avanço da globalização a partir da década de 1990, os países tiveram de reformular seus paradigmas administrativos, principalmente os referentes à atuação do Estado. Segundo Castells (1995), o controle estatal sobre o tempo e o espaço vem sendo sobrepujado pelos fluxos globais de capital, de produtos, serviços, tecnologia, comunicação e de informação; e os Estados que não forem capazes de se transformar nesse novo contexto histórico estarão arruinados. O Estado continua sendo um elemento essencial de regulação econômica, representação política e de assistência social, mas dentro de importantes limites estruturais e culturais, e com formas de atuação que são historicamente novas.

As grandes organizações, tanto as empresariais quanto as do crime, sobrepujaram as fronteiras geográficas e ampliaram muito o seu poder em detrimento do poder do Estado. Aqueles países em que "a casa ainda não estava arrumada" enfrentam grandes dificuldades de se articular para responder aos novos desafios. No caso do Brasil, como resolver o déficit de moradia nos grandes centros urbanos? De que modo conter a expansão acelerada do setor informal na economia? Como enfrentar o aumento da criminalidade e dos conflitos sociais por conta da pobreza e da falta de oportunidades? E quanto à gravidez na adolescência? E o número cada vez maior de jovens vivendo nas ruas, em meio à marginalidade e longe das salas de aula? E a prostituição, o desemprego e a desnutrição? Sem falar do abandono na velhice... Essas e tantas outras questões fizeram surgir um grande número de organizações que se propõem a fazer o trabalho que deveria ser feito pelo Estado. Se este 
investisse em educação de qualidade, capaz de atender a todos, a escola e a universidade poderiam ser suas grandes parceiras na solução desses problemas, possibilitando à cada indivíduo, a autonomia necessária para propor mudanças e transformar sua própria realidade.

Nesse sentido, Schwartzman (2004) afirma que os altos níveis de pobreza e exclusão no Brasil são causados por uma combinação de diversos fatores, e que o problema não vai ser solucionado apenas pela "vontade política" ou pela redistribuição da renda, mas pela educação:

Analistas que têm tratado do tema concordam que o maior correlato da desigualdade de renda no país são as diferenças em educação. Sem educação, é difícil conseguir emprego e, na ausência de uma população educada, poucos empregos de qualidade são criados. Com a escassez de educação, seu valor de mercado aumenta, e essa é uma das grandes causas da desigualdade de renda observada no país.

Portanto, a resposta a todos os questionamentos sobre o novo papel do Estado estaria simplesmente no investimento em desenvolvimento humano, principalmente, a partir da educação. Aqui cabe observar que, no período que vai de 1930 a 1989, o modelo de educação adotado no Brasil acabou aprofundando a hierarquização da divisão de trabalho. De acordo com Neves:

A formação profissional no Brasil estruturou-se mantendo uma natureza dual que, em nível técnico, significou uma segmentação hierarquizada da divisão entre trabalho intelectual e trabalho manual; em nível político, a divisão entre classes e frações de classe, consubstanciada no acesso seletivo aos diversos níveis e ramos de ensino, e, em nível administrativo, o acesso diferenciado às redes pública e privada de ensino (NEVES, 2000, p.67).

Já na década de 1970, Freire (2002) afirmava que por meio da educação seria possível mudar a relação entre opressores e oprimidos, pela autonomia que estes conquistariam a partir de uma maior capacidade de reflexão sobre o mundo e das possibilidades daí advindas. Nesse sentido, o movimento de incubação brasileiro tem contribuído para reduzir as desigualdades sociais, inclusive, o desemprego e o subemprego. Isso ocorre à medida que educa indivíduos com a finalidade de capacitá-los para serem empreendedores, atuando tanto em atividades tradicionais, quanto naquelas voltadas para as áreas tecnológica, rural, cultural ou social.

O novo papel do Estado se revela quando este apóia, direta ou indiretamente, as iniciativas das incubadoras de empreendimentos, incentivando desse modo a educação voltada para a consolidação das idéias e da autonomia dos cidadãos.

\section{A incubadoras de empresas e o rompimento do paradigma fordista}

De acordo com a Associação Nacional de Entidades Promotoras de Empreendimentos de Tecnologias Avançadas (Anprotec) (DORNELAS, 2002, p.21), as incubadoras são destinadas a amparar o estágio inicial de empresas nascentes que se enquadram em determinadas áreas de negócios, oferecendo-lhes assessoria gerencial, jurídica e contábil, além de infra-estrutura. A década de 1980 é apontada como o momento inicial desse movimento, que hoje é responsável pela criação de, em média, uma incubadora a cada dia.

A primeira incubadora sem fins lucrativos surgiu em Nova York, no final da década de 1950, como conseqüência imediata da proliferação dos parques tecnológicos nos EUA. No Brasil, as primeiras incubadoras tecnológicas nacionais surgiram nos municípios de São Carlos (SP), em 1985, em Florianópolis (SC), em 1986, e em Brasília (DF), em 1988, todas oriundas de universidades.

Até o início dos anos 1990, havia apenas sete incubadoras brasileiras. No entanto, a partir de 1995, o movimento de incubação ganhou impulso no Brasil, e no final daquela década é criada a Anprotec, para representar essas organizações junto ao Estado e apoiar o desenvolvimento do movimento de incubação no país, que em 2002 já contava com 159 incubadoras. 
Já em 2003, ainda segundo a Anprotec (2003), o Brasil tinha 207 incubadoras, que respondiam pela geração de 18.300 empregos. Dessas incubadoras, $40 \%$ desenvolviam atividades relacionadas com a produção de softwares; $20 \%$, de eletroeletrônicos e 19\%, desenvolviam atividades ligadas à Internet e ao comércio eletrônico. Havia naquele momento 71 incubadoras em fase de implantação. $\mathrm{O}$ total de empresas abrigadas era de 3.800. Cada incubadora era responsável, em média, pela criação de 13 novas empresas, gerando anualmente 2,6 mil novos empreendimentos. Outro dado levantado é o de que $90 \%$ das empresas que iniciam suas operações a partir de incubadoras conseguem ter lucro e forte representação no mercado em até três anos. Na maioria das vezes, essas organizações surgem nas universidades, a partir de pesquisas científicas dos acadêmicos ou por iniciativa de ex-alunos que em sociedade montam seu negócio a partir do que foi aprendido em sala de aula.

Existe uma grande diversidade de modelos de incubação e, como dito anteriormente, os empreendimentos podem ser tradicionais, de base tecnológica, cooperativas, estarem voltados para a cultura ou terem cunho social, como é o caso da Incubadora de Projetos de Profissionais e Empreendedores Afro-Brasileiros, mantida pelo Instituto Palmares de Direitos Humanos (IPDH). Lançada em agosto de 2004, no Rio de Janeiro, ela aplica a metodologia das incubadoras em iniciativas de economia solidária, e seu objetivo é minimizar a histórica discriminação sofrida pelo profissional negro.

Contudo, ainda que as incubadoras contribuam para criar novos postos de trabalho, nem todas rompem com o paradigma fordista. Para Tenório (2000), trata-se de um paradigma de organização da produção e do trabalho que, desde a época de Henry Ford, perpetua o fenômeno elitista; um fenômeno de classe que se materializa no interior das organizações, principalmente, nos níveis intermediários de decisão. A democratização da tomada de decisões, que gera a autonomia, é a medida da determinação da quebra do paradigma fordista. Logo, quanto mais hierarquizada for a organização e mais monológicas forem as ações gerenciais, mais evidente é a presença desse modelo.

Por sua vez, o modo de comunicação também permite identificar a presença do paradigma fordista numa organização. A efetiva comunicação possibilita a troca de idéias entre as individualidades. Contudo, segundo Cabral (2003), a comunicação exige que o emissor e o receptor se vejam como semelhantes, é essa semelhança é a condição para que haja verosimilhança. Pelo paradigma fordista a comunicação é monológica (TENÓRIO, 2000), pois ocorre numa única direção. Por conseguinte, sem a aceitação das semelhanças propostas por Castro (2004) não existiria uma comunicação efetiva.

Quando se observa as organizações surgidas do processo de incubação é possível verificar que em algumas incubadoras, o modo de organização da produção é inovador. Além do mais, quando desenvolvem suas idéias, geralmente, os novos empreendedores estão buscando sua autonomia; e esses indivíduos já contribuíram para reduzir as estatísticas de desemprego e subemprego.

Nas incubadoras sociais e de cooperativas, pelas próprias características dos projetos, todos os integrantes têm poder de decisão. Como exemplo, temos em Torres (2003) a discussão do caso da Incubadora Tecnológica de Campina Grande, que atuou junto à comunidade Recanto II - um assentamento do movimento dos sem-terra, que reúne 25 famílias de produtores rurais -, na qualificação e no desenvolvimento de tecnologias de produção de pescado no semi-árido paraibano.

No caso das incubadoras culturais e de negócios, a estrutura inicial dessas organizações coíbe o fordismo, pois não há sequer uma estrutura hierárquica. Porém, com o crescimento dessas entidades, é definido um modelo de organização produtiva, onde, presume-se, novamente o fordismo irá se consolidar nas relações de trabalho.

Assim, ao observarmos a experiência das incubadoras desenvolvidas no Brasil, percebe-se uma gradual ruptura do paradigma fordista, à medida que um número maior de pessoas passam a ter maior autonomia de decisão, principalmente as que vieram das universidades e que antes, na condição de subempregadas, estavam em grandes empresas, exercendo funções inferiores às suas qualificações. No entanto, ao verificarmos cada organização, separadamente, percebemos que seu crescimento tende à transformá-la numa organização fordista, exceto nos já mencionados empreendimentos sociais e nas cooperativas. 
Um experiência vista como alternativa ao pós-fordismo é o modelo de organização produtiva existente no nordeste da Itália, constituído por uma cadeia de pequenas e médias empresas. Quando analisa a participação do empresário nesse modelo, Gurisatti diz que

Embora os empresários acreditem nas leis do livre mercado, nos interesses individuais e assim por diante, e embora concentrem as próprias energias em cada fase do processo, eles tendem naturalmente a cooperar para o sucesso final da cadeia... Em um sistema não-fordista, participar é obrigatório: um empresário deverá participar do jogo coletivo da rede ou do distrito ou ficará isolado e sofrerá um redimensionamento social (apud COCCO et al. 2002, p.93).

No que se refere à participação do trabalhador, Gurisatti (apud COCCO et al. 2002) observa que essa participação é estimulada porque o trabalhador tem consciência de que pode controlar parte da produção e o valor do seu capital pessoal, já que num território com centenas de empresas similares está instado a escolher aquela que lhe oferece melhores condições e perspectivas de valorização. Gurisatti afirma que esse cenário desperta o interesse dos cientistas para o estudo do modelo não-fordista de desenvolvimento, devido ao retorno econômico e social conseguido com essa participação. Portanto, a inclusão social pela inovação nas relações de trabalho poder ser conseguida através da interação entre as diversas incubadoras, na tentativa de consolidação de redes não somente ideológicas e científicas, mas principalmente produtivas.

\section{Conclusão}

Há inovação nas relações de trabalho em algumas categorias de incubadoras de empreendimentos. Nas demais, ocorre uma melhora das estatísticas de exclusão social, na medida em que seus membros passam à condição de empreendedores e deixam de se submeter às opressivas relações de trabalho da organização fordista. Contudo, nem sempre a relação que eles mantêm com seus empregados é inovadora. Nesse caso, talvez a opressão seja mais branda, dependendo do histórico de vida do empresário. De qualquer modo, o movimento de incubação colabora para a reconstrução da identidade cultural brasileira, dando início a um processo histórico no qual o país começa a ser dono de seu destino, por meio de ações individuais, coletivas e globais que visam à inclusão social. Nesse processo, o assédio moral por que passa a maioria do povo brasileiro passa a ser enfrentado por um movimento em expansão, que anuncia uma grande mudança e que tem como exemplo a Incubadora Tecnológica de Campina Grande, na Paraíba. Nesse quadro, a mudança será tão maior quanto maior for o apoio do poder público e o esforço dos que buscam transformar o espaço e o tempo brasileiros. 


\section{Referências bibliográficas ${ }^{1}$}

ANPROTEC - Associação Nacional de Entidades Promotoras de Empreendimentos de Tecnologias Avançadas. Panorama 2003. Brasília, DF: Anprotec, 2003.

BOURDIEU, P. 0 poder simbólico. Tradução: Fernando Tomaz. Rio de Janeiro: Bertrand Brasil, 1989.

CABRAL, J. P. Semelhança e verossimilhança: horizontes da narrativa etnográfica. Mana - Estudos de Antropologia Social, Rio de Janeiro, v.9, n.1, p.109-22, 2003.

CASTELLS, M. The power of identity. New York: Blackbell, 1995.

CASTRO, E. V. A inconstância da alma selvagem. São Paulo: Cosac \& Naify, 2002.

COCCO, G.; URANI, A.; GALVÃO, A. P. (Org.). Empresários e empregos nos novos territórios produtivos: 0 caso da terceira Itália. Rio de Janeiro: DP\&A, 2002.

DE MASI, D. 0 ócio criativo. Tradução: Léa Manzi. Rio de Janeiro: Sextante, 2000.

DORNELAS, J. C. A. Planejando incubadoras de empresas. Como desenvolver um plano de negócios para incubadoras. Uma completa revisão sobre o movimento de incubadoras de empresas no Brasil e no exterior. Rio de Janeiro: Campus, 2002.

ELIAS, N. O processo civilizador: uma história dos costumes. Tradução: Ruy Jungmann. Rio de Janeiro: Jorge Zahar Editor, 1994.

FREIRE, P. Pedagogia do oprimido. 32. ed. Rio de Janeiro: Paz e Terra, 2002.

GUERREIRO RAMOS, A. A redução sociológica: introdução ao estudo da razão sociológica. 2. ed. Rio de Janeiro: Edições Tempo Brasileiro, 1965.

HIRIGOYEN, M. F. Assédio moral: a violência perversa do cotidiano. Tradução: Maria Helena Kühner. 3. ed. Rio de Janeiro: Bertrand Brasil, 2002.

NEVES, L. M. W. Brasil 2000: nova divisão de trabalho na educação. 2. ed. São Paulo: Xamã, 2000.

SCHWARTZMAN, S. As causas da pobreza. Rio de Janeiro: FGV, 2004.

TENÓRIO, F. G. Flexibilização organizacional: mito ou realidade? Rio de Janeiro: FGV, 2000.

TORRES, L. S. Influência do desenvolvimento tecnológico sobre o desenvolvimento social a partir das atividades da incubadora tecnológica de Campina Grande, Paraíba. Dissertação (Mestrado) - EAESP/FGV, São Paulo, 2003.

\footnotetext{
${ }^{1}$ Sítios visitados: Anprotec - Disponível em: <http://www.anprotec.org.br>. Acesso em: agosto de 2004; RelNC - Disponível em: <http://www.redetec.org.br/reinc/home_reinc.html>. Acesso em: agosto de 2004; e Ministério de Ciência e Tecnologia (MCT) - Disponível em: <http://www.mct.gov.br>. Acesso em: agosto de 2004.
} 